\title{
Prediction of Propeller Performance using Computational Fluid Dynamics Approach
}

\author{
Ahmad Fitriadhy ${ }^{\mathrm{a}, *}$, Nur Amira Adam ${ }^{\mathrm{b}}$, W. S. Kong ${ }^{\mathrm{c}}$, Faisal Mahmuddin ${ }^{\mathrm{d}}$, C. J. Quah ${ }^{\mathrm{e}}$ \\ aProgramme of Maritime Technology, School of Ocean Engineering, Universiti Malaysia Terengganu. Email: naoe.afit@gmail.com \\ ${ }^{\text {b}}$ Programme of Maritime Technology, School of Ocean Engineering, Universiti Malaysia Terengganu. Email: amiraadam.nur@gmail.com \\ 'Programme of Maritime Technology, School of Ocean Engineering, Universiti Malaysia Terengganu. Email: wsheng_95@ hotmail.com \\ ${ }^{\mathrm{d}}$ Marine Engineering Department, Engineering Faculty, Hasanuddin University. Email: f.mahmuddin@gmail.com

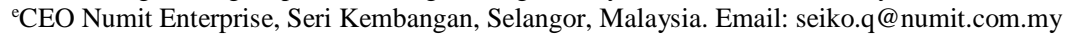

\begin{abstract}
A reliable prediction approach to obtain a sufficient thrust and torque to propel the ship at desired forward speed is obviously required. To achieve this objective, the authors propose to predict the thrust coefficient $\left(\mathrm{K}_{\mathrm{T}}\right)$, torque coefficient $\left(\mathrm{K}_{\mathrm{Q}}\right)$ and efficiency $(\eta)$ of the propeller in open-water model test condition using Computational Fluid Dynamics (CFD) simulation approach. The computational simulation presented in the various number of rotational speed (RPM) within the range of advance ratio $\mathrm{J}=0.1$ up to 1.05 . The higher value of $\mathrm{J}$ leads to a decrease in $10 \mathrm{~K}_{\mathrm{Q}}$ and $\mathrm{K}_{\mathrm{T}}$. While the $\eta$ increased steadily at the lower value of $\mathrm{J}$ and decreased at the higher value of $\mathrm{J}$. The results also showed that the propeller with $1048 \mathrm{rpm}$ obtains a better efficiency at $\mathrm{J}=0.95$ with $\eta=88.25 \%, 10 \mathrm{~K}_{\mathrm{Q}}=0.1654$ and $\mathrm{K}_{\mathrm{T}}=0.0942$. The computation result is very useful as preliminary data for propeller performance characteristics.
\end{abstract}

Keywords: CFD; efficiency; propeller; RPM; thrust

\section{Introduction}

The main purpose of a marine propeller to deliver the power and torque provided by the engine into the rotational motion to generate thrust. A proper specification of propeller design is required to make sure the propeller can produce a driving force to move the ship forward in the most effective ways $[1,2]$. Other than that, improper propeller design and specification have a direct influence on the reduction of propeller performance and fuel efficiency of the ship propulsion system $[3,4]$. The configuration of the propeller becomes a typical discussion among the naval architectures because the selection of the proper propeller design depends on the specification of the vessel and it also affects the manufacturing cost. Therefore, a hydrodynamics characteristic of the propeller is a very prominent aspect to be analysed in the early design stage using several methods in the form of open-water propeller model test.

Several researchers have been investigating the hydrodynamics characteristics of propeller using numerical

\footnotetext{
${ }^{*}$ Corresponding author. Tel.: +6-09-668-3350

Programme of Maritime Technology, School of Ocean

Engineering, Universiti Malaysia Terengganu

Kuala Terengganu, Terengganu, 21030
}

and experimental approaches. According to [5-8], mathematical methods can be used to predict the hydrodynamics characteristics of the propeller based on circulation or lifting line theory. Meanwhile, hydrodynamics characteristics of the propeller are also predicted by using an experimental model test with towing tank [9-11]. This experimental method is very expensive, time-consuming, and have a complex procedure for various hydrodynamics analysis test configuration. Following the works of [12-16], the numerical methods are adopted to solve and analyze the fluid problem. The computational fluid dynamics (CFD) simulation are the best alternative with several advantages such as allow to simulate using actual and model geometry scale in extreme condition of the fluid flow and the CFD simulation also have a good agreement with experimental data [17-20].

This paper presents a CFD simulation approach for the extension work from [21, 22] to access the performance of propeller by $\mathrm{K}_{\mathrm{T}}, \mathrm{K}_{\mathrm{Q}}$, and $\Pi$ of the propeller. Here, a commercial CFD software, namely NUMECA Fine $^{\mathrm{TM}} /$ Turbo $\mathrm{v} 12.2$ is utilized by grid generation, flow solver and post-processing capabilities. Fine $\mathrm{T}^{\mathrm{TM}} / \mathrm{Turbo}$ is specialized to simulate internal, rotating and turbomachinery flows for all types of fluids. The package has a fully hexahedral and highly automated grid generation module 
AutoGrid $^{\mathrm{TM}}$. The package uses a 3D Reynolds Averaged Euler and Navier Stokes flow solver EURANUS. CFView ${ }^{\mathrm{TM}}$ is a post-processing module which is also part of the package. Basically, this is solved by means of a gridindependent study to estimate the optimal domain discretization. In this computation simulation, several numbers of rotational speed (rpm) are considered. The result is then comprehensively discussed to analyze their effect on $\mathrm{K}_{\mathrm{T}}, \mathrm{K}_{\mathrm{Q}}$, and $\eta$ with the purpose of quantifying propeller performance quality.

\section{Methods and Material}

\subsection{Governing equation}

The cornerstone of computational fluid dynamics application, there is consists of fundamental governing mathematical statements of fluid dynamics such as continuity, momentum, and energy conservation equation. The 3-D propeller simulation defines that the flow around the propeller is complex, due to the combination between rotation and progression into the water [3]. Therefore, the CFD flow solver (ISIS-CFD) on NUMECA Fine ${ }^{\mathrm{TM}} / \mathrm{Turbo}$ V12.2 was based on the incompressible unsteady ReynoldsAveraged Navier-Stokes equation (URANSE) in which the solver applied the Finite Volume Method for representing the inflow and outflow areas, where the fluid flow is well behaved. Here, the governing equation has been discriminated using a Finite Volume Method with the velocity-pressure coupling and operated using a SIMPLE algorithm [23]. The Finite Volume Method also able to directly apply the integral spatial discretization in the physical space coordinate transformation to a computational space and this method also flexible to complex geometry structured and unstructured meshes.

\subsection{Governing equation}

To carry out the application of general conservation form of the Navier-Stokes equation using Finite Volume Method, the model of a finite volume has been considered fixed in space and the fluid element is moving. The continuity equation in conservation form presented in Eq. (1), where the $\boldsymbol{\rho}=$ density, $U_{i}$ is the averaged Cartesian components of the velocity-vector in $i^{\text {th }}$ direction $(i=1,2,3)$. Since the propeller simulated in steady and constant density of incompressible flows, the continuity equation has been modified as Eq. 2 [11].

$$
\begin{gathered}
\frac{\partial \rho}{\partial t}+\frac{\partial}{\partial_{x_{i}}}\left(\rho u_{i}\right)=0 \\
\frac{\partial}{\partial_{x_{i}}}\left(\rho u_{i}\right)=0
\end{gathered}
$$

Newton's $2^{\text {nd }}$ law has been applied in Finite Volume Method to a model of the fluid flow. When the fluid element moving, the net force on the fluid element equals its mass times the acceleration of the element. Therefore, the global Navier-Stokes equation applied the principle of the linear momentum conservation to solve the problem. Here, the momentum conservation equation expressed as Eq. 3.

$$
\begin{aligned}
& \frac{\partial}{\partial t}\left(\rho u_{i}\right)+\frac{\partial}{\partial x_{j}}\left(\rho u_{j} u_{i}\right) \\
& =-\frac{\partial p}{\partial x_{i}}+\frac{\partial \tau_{i j}}{\partial x_{j}}+\rho g_{i}+F_{i}
\end{aligned}
$$

where $p=$ static pressure, $g_{i}=$ gravitational acceleration, $F_{i}$ $=$ external body force in an averaged Cartesian component of the velocity-vector in $\mathrm{i}^{\text {th }}$ direction $(\mathrm{i}=1,2,3)$ and $\delta_{i j}=$ Kroneker delta and is equal to unity $i=j$ and zero when $i \neq$ $j$ [12]. Finally, $\tau_{i j}$ defined Reynolds-stress tensor presented below as Eq. 4, where $\mu$ being the dynamics viscosity [3].

$$
\tau i j=\left[\mu\left(\frac{\partial u_{i}}{\partial x_{j}}+\frac{\partial u_{j}}{\partial x_{i}}\right)-\frac{2}{3} \mu \frac{\partial u_{i}}{\partial x_{j}} \delta_{i j}\right]
$$

\subsection{Turbulent model}

During the simulation, a simple one-equation model has relatively applied to compute rotating motions of propeller. Deck [24], Kostic [25], Hejlesen [26] and Lorin [27], reported that the Spalart-Allmaras transports equation model made for eddy viscosity and not required finer grid resolution to capture the velocity field gradients with algebraic models. For internal flow (turbomachinery) application, the kinematic turbulent $v_{t}\left(\mathrm{~m}^{2} / \mathrm{s}\right)$ in this model can be specified and estimate based on the assumptions, $\frac{v t}{v}=1$ to 5 [28]. Here, the transport model for the working variable is shown in Eq. 5:

$$
\begin{aligned}
& \frac{\partial \rho \tilde{v}}{\partial t}+\frac{\partial \rho u_{j} \tilde{v}}{\partial x_{j}}=\frac{\partial}{\partial x_{j}}\left[\left(\mu+\frac{\mu_{\tau}}{\sigma}\right) \frac{\partial \tilde{v}}{\partial x_{j}}\right] \\
& +c_{b 2} \frac{\partial \tilde{v}}{\partial x_{j}} \frac{\partial \rho \tilde{v}}{\partial x_{j}}+c_{b 1} \rho \tilde{W} \tilde{v}-c_{w 1} f_{w} \rho\left(\frac{\tilde{v}}{y}\right)
\end{aligned}
$$

The eddy viscosity and damping function are defined as Eqs. 6 and 7, respectively. Where, $x=\frac{\tilde{v}}{v}$ and the kinematic viscosity $v=\mu / \rho$.

$$
\begin{gathered}
\mu_{\tau}=f_{v 1} \rho \tilde{v} \\
f_{v 1}=\frac{X^{3}}{X^{3}+c_{v 1}^{3}}
\end{gathered}
$$


It should be noted here that the best practice in turbulence modeling quantities by considering an appropriate grid to estimate the cell meshing size, $y_{\text {wall }}$. Referring to the transport model discussed above, the viscosity has been taken into account that presents the high gradients near solid wall layers. Therefore, it is very important to have a sufficient amount the number of grid points in the boundary layers to properly capture the high gradient [21]. Here, an appropriate estimation of cell meshing size, $y_{\text {wall }}$ for Navier-Strokes simulation, depends on the wall variable $y^{+}$to measure the viscosity effect region as written in Eq. (8) [29].

$$
y_{1}^{+}=\frac{\rho u_{\tau} y_{\text {wall }}}{\mu}
$$

where $u_{\tau}$ is the friction velocity, $u_{\tau}=\sqrt{\frac{\tau_{\text {wall }}}{\rho}}--\sqrt{\frac{1}{2}\left(V_{\text {ref }}\right)^{2} C_{f}}$. It is clear that the value of $y_{\text {wall }}$ depends on the value of $y_{1}{ }^{+}$.

In addition, the estimation for $y_{\text {wall }}$ as a function of the desired value is obtained using a truncated series solution of the Blasius equation as expressed in Eq. (9).

$$
y_{\text {wall }}=6\left(\frac{V_{r e f}}{v}\right)^{\frac{-7}{8}}\left(\frac{L_{r e f}}{2}\right)^{\frac{1}{8}} y_{1}^{+}
$$

Note that the reference velocity, $V_{\text {ref }}$, can be taken from the body velocity. The reference length, $L_{r e f}$, should be based on the body length since an estimation of the boundary layer thickness is implied in this calculation. For instance, in the case of a propeller simulation, one could use the propeller diameter, as reference length. This is approximate, of course, as the thickness of the boundary layer will vary widely within the computational domain. Fortunately, it is only necessary to place within a range and not at a specific value.

\subsection{Hydrodynamics theory of propeller}

In CFD computation, the rotational surface is utilized to compute the force and torque of the system, where the axial thrust projected by the global force on the rotational axis and the torque was exerted by the global force calculated at $(0,0,0)$. Nevertheless, these quantities are computed from the pressure and the velocity fields of the fluid acting on the blade surfaces. The axial thrust is computed based on Eq. 12 [28];

$$
\sum_{S} \vec{F} \cdot \vec{n}_{z}
$$

The projection of the torque along a given direction $\vec{Z}$ is given by

$$
\left[\sum_{S} \vec{r} \times \vec{F}\right] \cdot \vec{z}
$$

The propeller model has been tested in open water test to determine the intrinsic propeller performance without distributed by the ship when it moved forward. The computed result from CFD usually refers to thrust (T), torque $(\mathrm{Q})$ and efficiency $(\eta)$. Thus, the performance data are given as form dimensionless thrust coefficient $\left(K_{T}\right)$ and torque coefficient $\left(K_{Q}\right)$ to be plotted against the advance ratio $(\mathrm{J})$. The dimensionless quantities are defined as

$$
\begin{gathered}
J=\frac{V_{a}}{n \cdot D} \\
K_{T}=\frac{T}{\rho n^{2} D^{4}} \\
K_{Q}=\frac{Q}{\rho n^{2} D^{5}} \\
\eta=\frac{J}{2 \pi} \frac{K_{T}}{K_{Q}}
\end{gathered}
$$

where $\rho$ is the water density, $n$ the number of propeller rotations per second (RPS), $D$ the propeller diameter and $v_{a}$ represents for water advance velocity $(\mathrm{m} / \mathrm{s})$.

\section{Simulation Condition}

\subsection{Hydrodynamics theory of propeller}

In this paper, different rotational speeds were used to investigates. The principal dimension of the propeller, which composes with four number of blades is clearly presented in Table 1 and Fig. 1.

Table 1. Principle dimensions of propeller

\begin{tabular}{ccc}
\hline Geometrical parameters & Full Scale & Model Scale \\
\hline Diameter $(\mathrm{mm})$ & 3650 & 119.25 \\
AE/AO & 0.695 & 0.695 \\
P/D & 1.013 & 1.013 \\
Pitch (mm) & 3697.45 & 120.83 \\
Scale & \multicolumn{2}{c}{$1: 30.6$}
\end{tabular}

Propeller Orientation Right-hand rotation

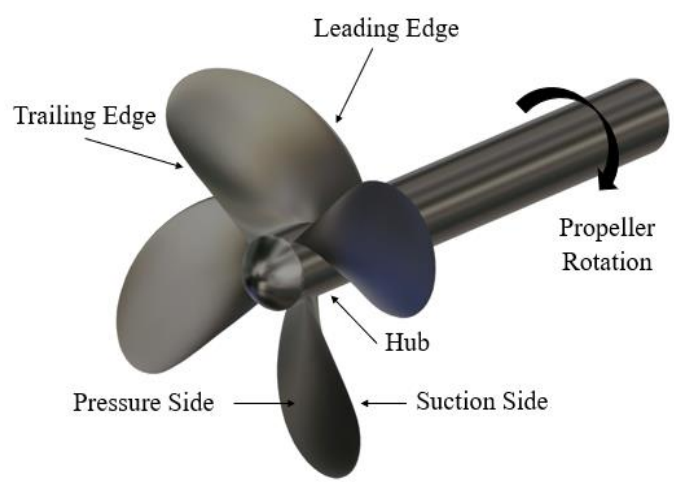

Figure 1.3D view of propeller geometry 
Table 2. The simulation conditions

\begin{tabular}{cc}
\hline Rotational Speed (RPM) & Number of blades (Z) \\
\hline 1048 & 4 \\
1200 & \\
1340 & \\
\hline
\end{tabular}

\subsection{Simulation condition}

In this study, there are parametric studies to be focused to achieve the objectives. The parametric studies were based on Table 2.

\subsection{Computational domain and grid generation}

The numerical simulation of propeller performance in various configurations was developed from the commercial software NUMECA Fine ${ }^{\mathrm{TM}} /$ Turbo. Here, a single propeller blades geometry needs to define the trailing edge, leading edge, pressure side, suction side, and the hub of the propeller to generate an automatic grid. This simulation only considered a single blade of the propeller and another blades are performed by using a rotational periodicity (number of blades) which is the block of the blades and boundary are repeated in a given axis by a specified angle to save the computational time (for all simulation condition) [30].

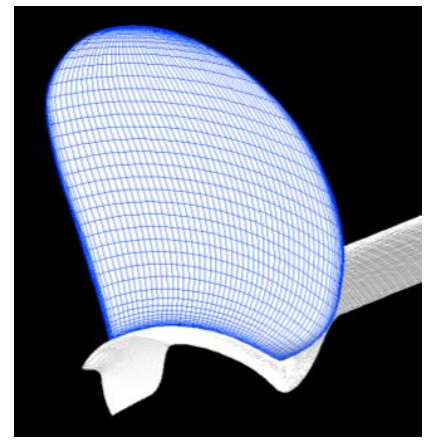

Figure 2. 3D surface mesh for single blade associated with $Z=4$ mesh model

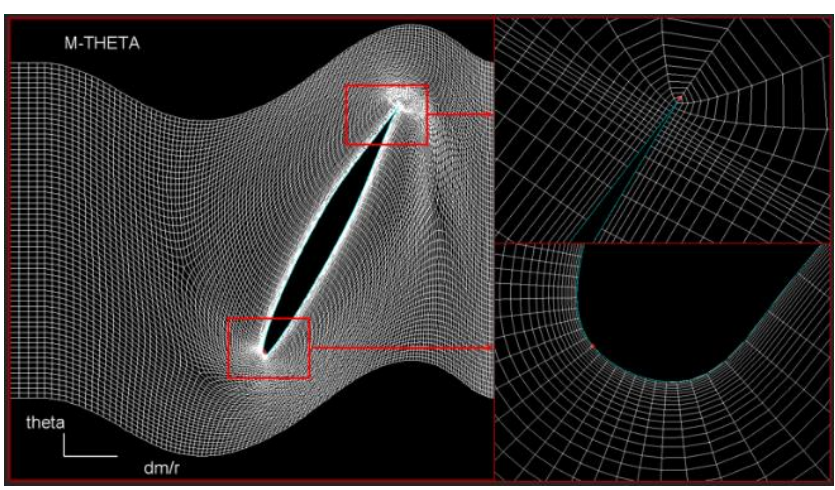

Figure 3. Local refinement of the block structured grid in Blade-to-Blade view

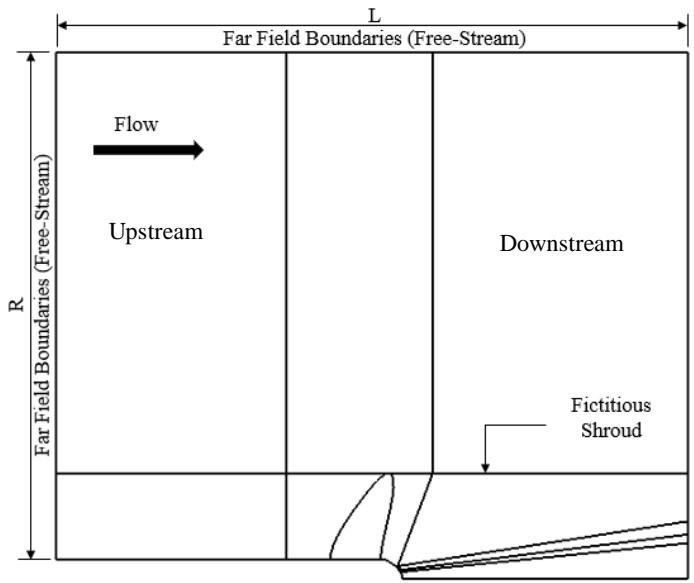

Figure 4. Upstream and downstream location in the domain

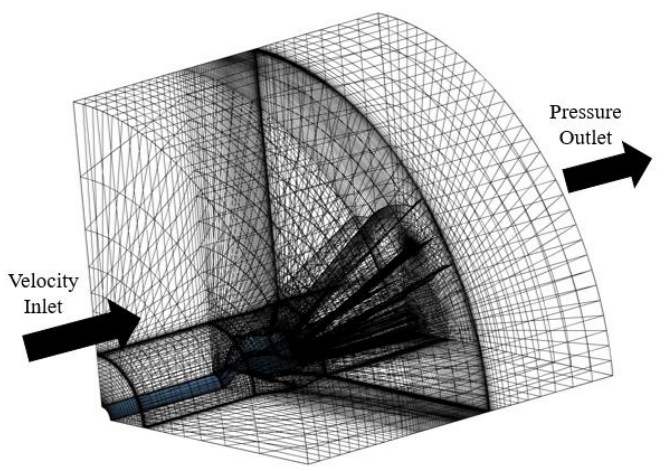

Figure 5. Upstream and downstream location in the domain

Referring to Figure 4, the far-field boundary extends radially at five times $(5 \mathrm{R})$ the rear rotor radius at rotation center, while the axial length was located at three times radius $(3 R)$ for inlet and outlet boundary from the center as well. The inlet was specified as having a constant velocity of the flow model and a static pressure has been imposed at outlet boundary as shown in Fig. 5.

Table 3. Mesh Independent study on propeller geometry

\begin{tabular}{ccccc}
\hline Case & $\begin{array}{c}\text { Total Number of } \\
\text { Cell Meshing }\end{array}$ & $\mathrm{K}_{\mathrm{T}}$ & $10 \mathrm{~K}_{\mathrm{Q}}$ & $\eta$ \\
\hline $\mathrm{A}$ & $1,789,042$ & 0.3679 & 0.5541 & 0.1057 \\
$\mathrm{~B}$ & $2,559,546$ & 0.3719 & 0.5563 & 0.1064 \\
$\mathrm{C}$ & $2,817,090$ & 0.3727 & 0.5571 & 0.1065 \\
$\mathrm{D}$ & $4,000,666$ & 0.3744 & 0.5551 & 0.1073 \\
\hline
\end{tabular}

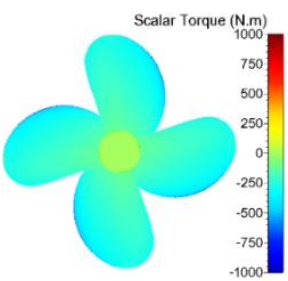

(a)

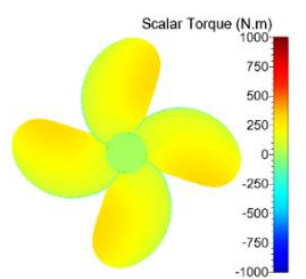

(b)
Figure 6. Scalar torque contour for (a) pressure and (b) suction side at $\mathrm{J}=0.1$ with $1048 \mathrm{RPM}$ 
The value for the rotational speed of the solid boundary condition types (blades and hub) was set as a positive value to indicates a propeller rotational in positive $\theta$-direction according to a right-handed propeller orientation [28]. Since this computational have a complex fluid problem, the Merkle preconditioner has been selected to increase the convergence rate and computation efficiency at very low flow speed $[32,30]$. Besides, to overcome an insufficient calculation due to low relative edge cell size, a double solver precision has been selected to solve this computation and has led to increasing the required memory. The average duration of every simulation was about 4 to 7 hours (double solver precision) on a HP Z820 Workstation PC with processor Intel® Xeon® CPU ES-2690 v2 @ 3.0GHz (2 processor) associated with the installed memory RAM of $32.0 \mathrm{~GB}$ and 64-bit operating system

The meshing generation of the propeller was created in AutoGrid5 v12.2 software. It should note that an adequate number of mesh is very important for proper and accurate simulation. Hence, a mesh independent study may need to be performed for four different total number of cell meshing. Referring to mesh independent study result, the case $\mathrm{C}$ with 2.8 million total number of cell meshing was selected in all computed simulation of the propeller model accuracy of the CFD solution. This can be explained by the fact the 4.0 million total number of cell meshing were unnecessary due to its insignificant influence on the computational result of the thrust coefficient, torque coefficient, and efficiency. In the final stage of the CFD simulation, a package software in $\mathrm{CFV}$ iew was used to visualize the scalar torque for pressure and suction side for all various configurations of the propeller as displayed in Fig. 6.

\section{Results and Discussions}

The analysis for thrust coefficient, torque coefficient, and efficiency of the propeller in various rotational speed (RPM) was analyzed in the steady-state have been presented and appropriately discussed. In this study, the Computational Fluid Dynamics (CFD) approach was utilized to obtain the propeller performance.

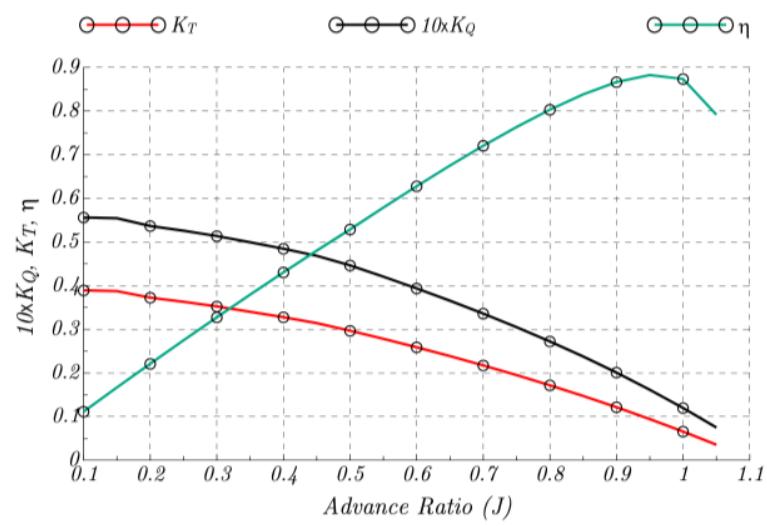

Figure 7. Thrust coefficient, torque coefficient, and efficiency for 1048 RPM

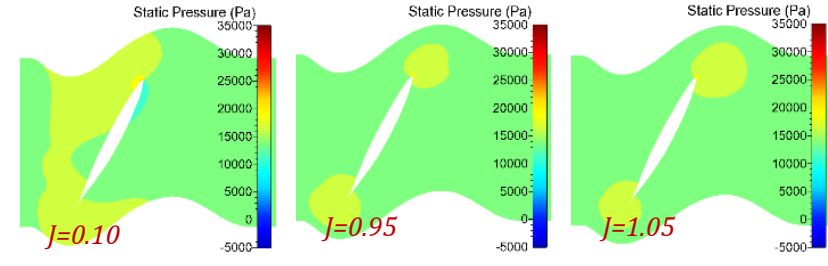

Figure 8. 2D static pressure contour for 1048 RPM
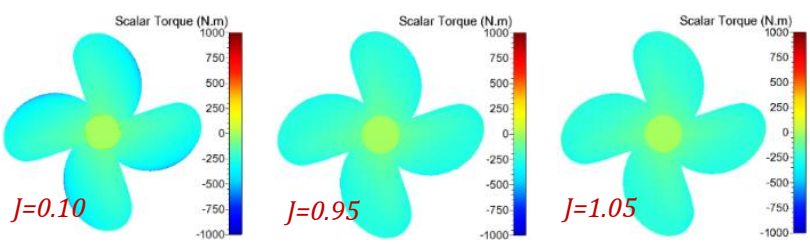

Figure 9. Scalar torque contour at pressure side for 1048 RPM

\subsection{Propeller performance in various rotational speed}

Referring to the Fig. 7 , the $\mathrm{K}_{\mathrm{T}}$ and $10 \mathrm{~K}_{\mathrm{Q}}$ decreases by increasing the advance ratio, J. Besides, the $\eta$ increase steadily at lower advance ratio $(\mathrm{J}=0.10)$ up to propeller optimum value $(\mathrm{J}=0.95)$ and decreased at higher advance ratio $(\mathrm{J}=1.00$ and 1.05) as showed in Fig. 7 and detailed value in Table 4 . The effect to the $\mathrm{K}_{\mathrm{T}}$ occurs due to low axial velocity, the water surrounding the propeller will be accelerated from a low velocity. While at the higher advance ratio, the water surrounds the propeller already moving at high velocity and makes less change to the water velocity [33]. Besides that, the effect of $10 \mathrm{~K}_{\mathrm{Q}}$ due to the decreasing drag force on the blade surface. According to [33], the water pressure surrounding the blade was high when the water condition at a low velocity and directly contributes to pressure drag on the blade surface. While at high water velocity, the water pressure surrounding the blades will drop slowly and the pressure drag also drops as shown in Figure 8. This can be explained by the fact that the lowest pressure drags at leading edge (light blue color) resulted in lower scalar torque value as presented in Fig. 9.

The result of testing the propeller model on the various rotational speed of 1048, 1200 and 1340 RPM are represented in Fig. 10. The results showed that the $10 \mathrm{~K}_{\mathrm{Q}}, \mathrm{K}_{\mathrm{T}}$ and $\eta$ value obviously had a similar trend with the results at $1048 \mathrm{rpm}$ from $\mathrm{J}=0.10$ up to 1.05 . Generally, the comparison between these three numbers of rpm shows that increasing the rpm results in decreasing $10 \mathrm{~K}_{\mathrm{Q}}, \mathrm{K}_{\mathrm{T}}$ and $\eta$ of the propeller. The propeller optimum, for $1048 \mathrm{rpm}$ at about $\mathrm{J}=$ 0.95 was achieved at $\eta=88.25 \%$ with $10 \mathrm{~K}_{\mathrm{Q}}=0.1614$ and $\mathrm{K}_{\mathrm{T}}=0.0942$. Besides, the optimum efficiency of the propeller for 1200 RPM occurs at $J=0.90$ with $\eta=73.93 \%$, $10 \mathrm{~K}_{\mathrm{Q}}=0.2318$, and $\mathrm{K}_{\mathrm{T}}=0.1021$. While, the optimum $\mathrm{J}$ value for $1340 \mathrm{rpm}$ at about $\mathrm{J}=0.85$ with $67.41 \%, 10 \mathrm{~K}_{\mathrm{Q}}=0.2318$, and $\mathrm{K}_{\mathrm{T}}=0.1298$. As compared with various rotational speeds, the propeller with 1048 RPM obtains better efficiency that can be explained by the fact that the propeller with low RPM will absorb less power to achieve requested RPM. According to [34] and [35], the propeller rotation speed greatly influences the blades pressure distribution where the higher rpm resulting in the lower pressure at the 
blade surface; where blue color indicates low pressure area increase as higher propeller revolution (see Fig. 11). Meanwhile, the negative pressure magnitude direction being against the propeller continued to increase and expand in the back region. In this situation, the hydrodynamics performance of the 1340 RPM shows that the propeller with high rpm will produce lower pressure at suction side.
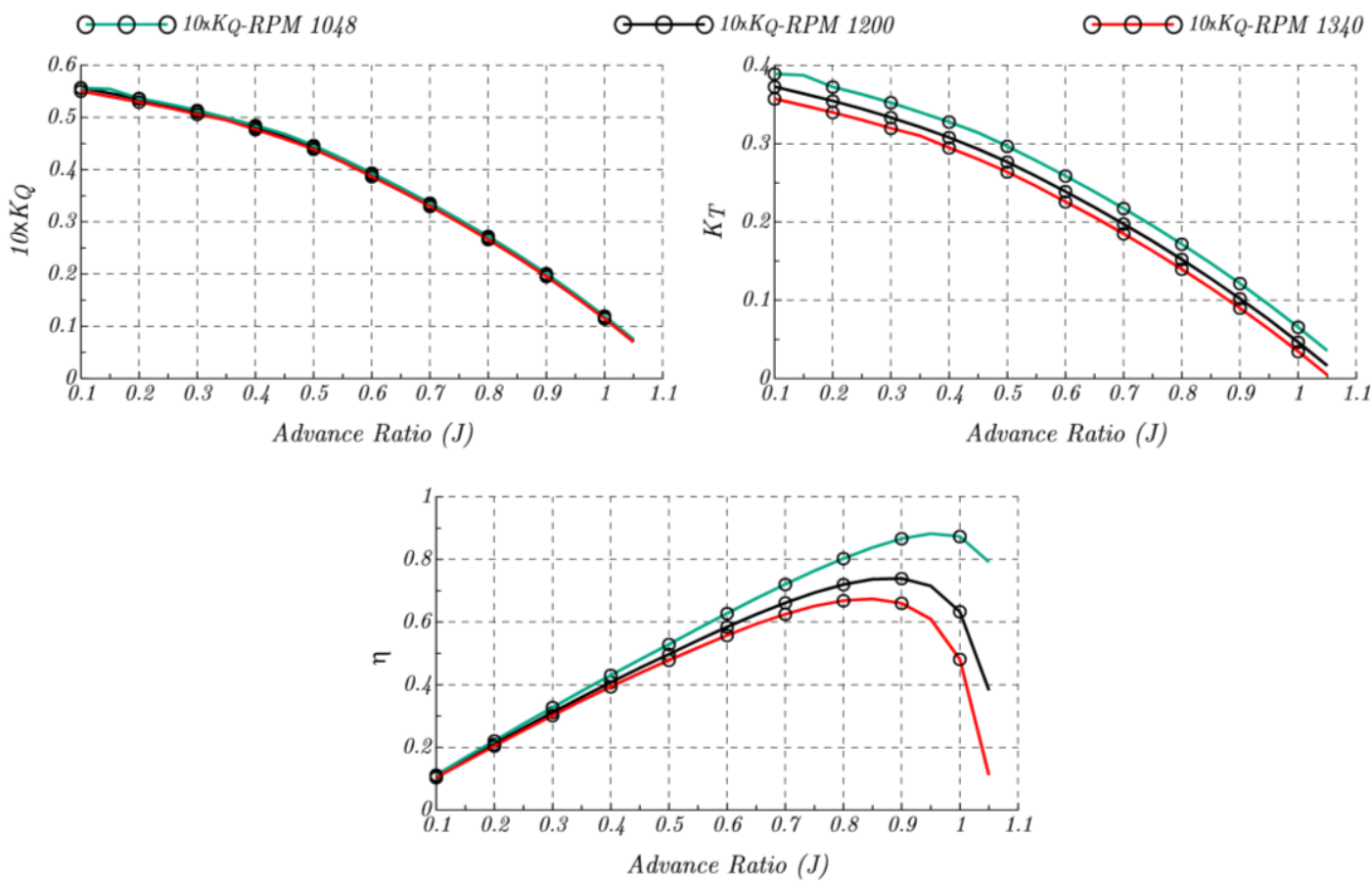

Figure 10. Thrust coefficient, torque coefficient, and efficiency for various rotational speeds

Table 4. Thrust coefficient, torque coefficient, and efficiency for various rotational speeds

\begin{tabular}{cccccccccc}
\hline \multirow{2}{*}{$\mathrm{J}$} & \multicolumn{3}{c}{$1048 \mathrm{RPM}$} & \multicolumn{3}{c}{$1200 \mathrm{RPM}$} & \multicolumn{3}{c}{$1340 \mathrm{RPM}$} \\
\cline { 2 - 10 } & $10 \mathrm{~K}_{\mathrm{Q}}$ & $\mathrm{K}_{\mathrm{T}}$ & $\eta$ & $10 \mathrm{~K}_{\mathrm{Q}}$ & $\mathrm{K}_{\mathrm{T}}$ & $\eta$ & $10 \mathrm{~K}_{\mathrm{Q}}$ & $\mathrm{K}_{\mathrm{T}}$ & $\eta$ \\
\hline 0.10 & 0.5562 & 0.3892 & 0.1114 & 0.5571 & 0.3727 & 0.1065 & 0.5505 & 0.3573 & 0.1033 \\
0.15 & 0.5545 & 0.3873 & 0.1668 & 0.5464 & 0.3638 & 0.1590 & 0.5401 & 0.3488 & 0.1542 \\
0.20 & 0.5367 & 0.3725 & 0.2209 & 0.5355 & 0.3546 & 0.2108 & 0.5296 & 0.3399 & 0.2043 \\
0.25 & 0.5258 & 0.3630 & 0.2747 & 0.5238 & 0.3445 & 0.2617 & 0.5184 & 0.3303 & 0.2535 \\
0.30 & 0.5137 & 0.3524 & 0.3276 & 0.5109 & 0.3334 & 0.3116 & 0.5061 & 0.3197 & 0.3016 \\
0.35 & 0.4993 & 0.3401 & 0.3794 & 0.4968 & 0.3213 & 0.3603 & 0.4949 & 0.3100 & 0.3490 \\
0.40 & 0.4846 & 0.3277 & 0.4305 & 0.4808 & 0.3079 & 0.4077 & 0.4768 & 0.2948 & 0.3936 \\
0.45 & 0.4684 & 0.3141 & 0.4802 & 0.4628 & 0.2930 & 0.4534 & 0.4593 & 0.2802 & 0.4370 \\
0.50 & 0.4464 & 0.2967 & 0.5288 & 0.4425 & 0.2766 & 0.4974 & 0.4391 & 0.2639 & 0.4782 \\
0.55 & 0.4206 & 0.2781 & 0.5788 & 0.4174 & 0.2583 & 0.5416 & 0.4144 & 0.2455 & 0.5187 \\
0.60 & 0.3936 & 0.2588 & 0.6278 & 0.3903 & 0.2389 & 0.5845 & 0.3866 & 0.2258 & 0.5577 \\
0.65 & 0.3654 & 0.2385 & 0.6752 & 0.3619 & 0.2186 & 0.6248 & 0.3590 & 0.2061 & 0.5938 \\
0.70 & 0.3359 & 0.2173 & 0.7206 & 0.3325 & 0.1975 & 0.6616 & 0.3296 & 0.1850 & 0.6254 \\
0.75 & 0.3049 & 0.1950 & 0.7635 & 0.3017 & 0.1754 & 0.6940 & 0.2986 & 0.1629 & 0.6510 \\
0.80 & 0.2722 & 0.1717 & 0.8031 & 0.2691 & 0.1522 & 0.7201 & 0.2662 & 0.1398 & 0.6686 \\
0.85 & 0.2376 & 0.1472 & 0.8383 & 0.2344 & 0.1277 & 0.7368 & 0.2318 & 0.1155 & 0.6741 \\
0.90 & 0.2009 & 0.1215 & 0.8665 & 0.1978 & 0.1021 & 0.7393 & 0.1952 & 0.0900 & 0.6602 \\
0.95 & 0.1614 & 0.0942 & 0.8825 & 0.1587 & 0.0751 & 0.7155 & 0.1560 & 0.0629 & 0.6099 \\
1.00 & 0.1196 & 0.0656 & 0.8735 & 0.1168 & 0.0465 & 0.6336 & 0.1144 & 0.0346 & 0.4813 \\
1.05 & 0.0750 & 0.3892 & 0.7917 & 0.0722 & 0.0165 & 0.3822 & 0.0698 & 0.0047 & 0.1117 \\
\hline
\end{tabular}



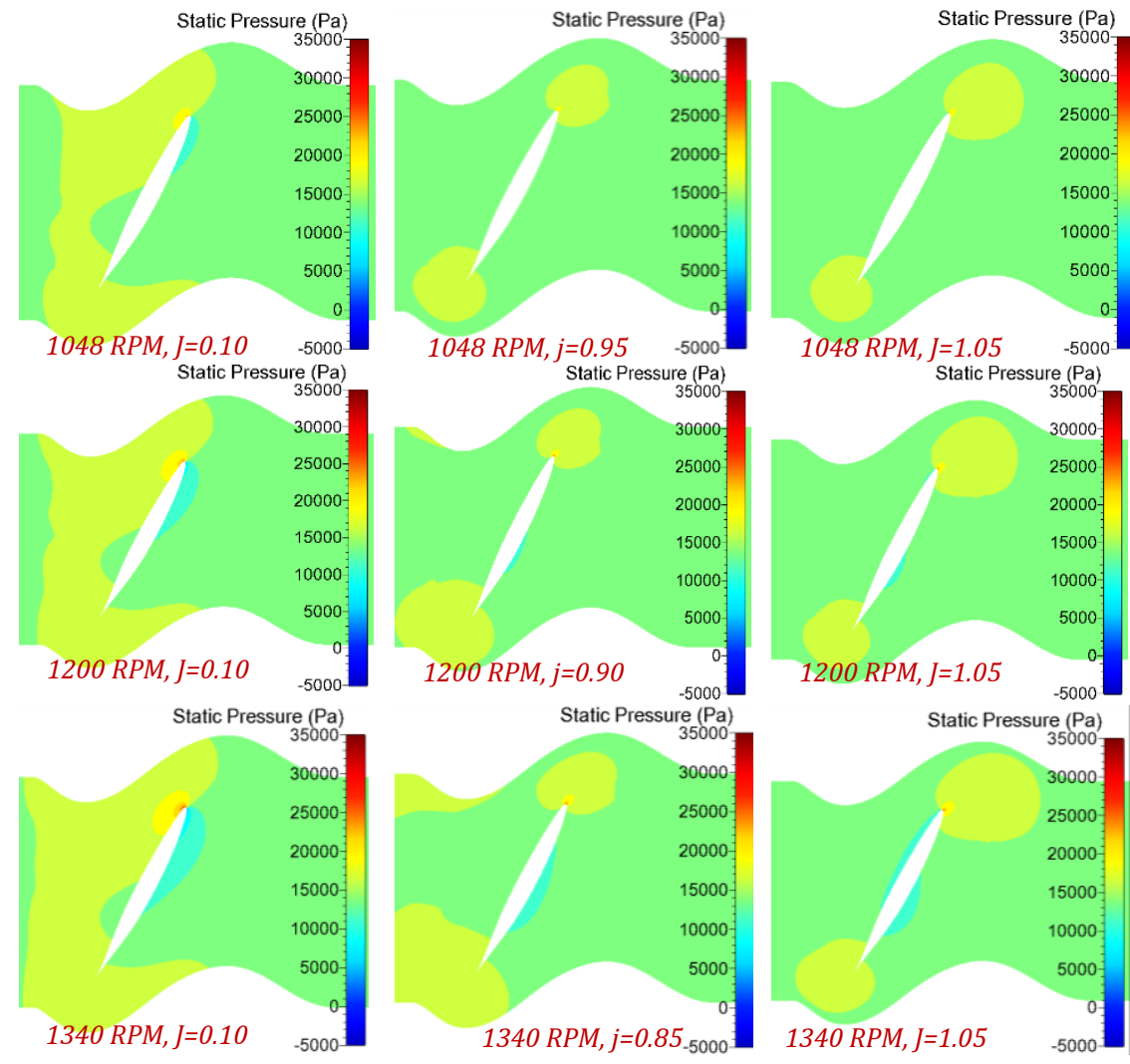

Figure 11. 2D static pressure contour for various rotational speed
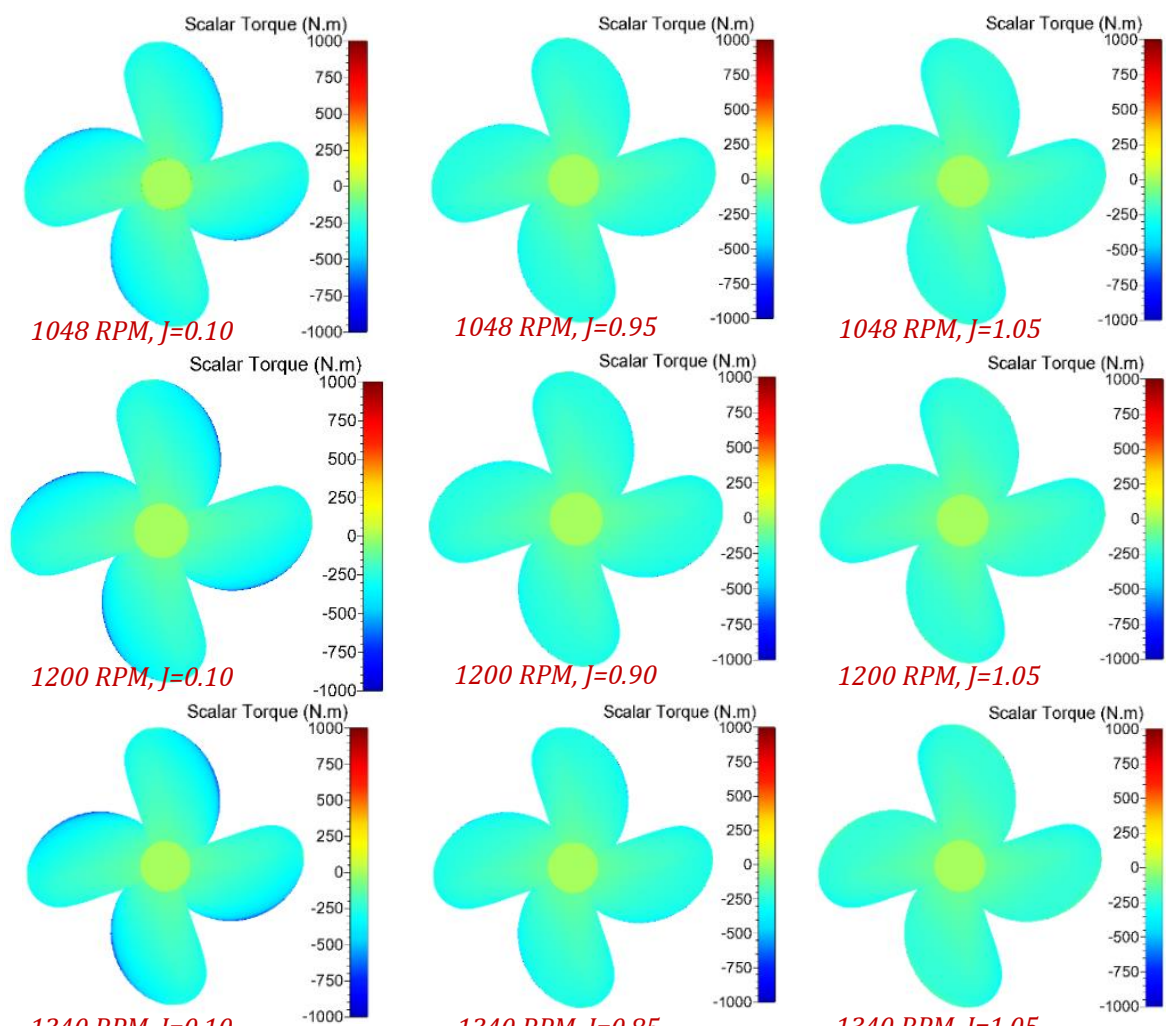

$1340 R P M, J=0.10$

1340 RPM $J=0.85$

1340 RPM, J=1.05

Figure 12. Scalar torque contour at pressure side for various rotational speed 


\section{Conclusion}

The Computational Fluid Dynamics (CFD) simulation on hydrodynamic analysis of propeller is performed using NUMECA Fine ${ }^{\mathrm{TM}} /$ Turbo v.12.2 software. The analysis of propeller performance was summarized as follow:

- The higher value of $\mathrm{J}$ lead to decrease $10 \mathrm{~K}_{\mathrm{Q}}, \mathrm{K}_{\mathrm{T}}$, and $\eta$ due to low axial velocity and pressure drag surrounding the propeller.

- The increasing number of rotational speed (RPM), will decrease the propeller performance $\left(10 \mathrm{~K}_{\mathrm{Q}}, \mathrm{K}_{\mathrm{T}}\right.$ and $\left.\eta\right)$.

- As compared with various numbers of rpm, the optimum efficiency of the propeller with 1048 RPM at $\mathbf{J}=0.95$ with $\eta=88.25 \%, 10 \mathrm{~K}_{\mathrm{Q}}=0.1614$ and $\mathrm{K}_{\mathrm{T}}=0.0942$ produce a better efficiency.

In general, the effect of various rotational speeds has a positive influence on the open water characteristics of the marine propeller. Therefore, these CFD results are useful as a preliminary prediction of propeller performance.

\section{Acknowledgments}

The authors wish to greatly thank for the PT. Terafulk Megantara Design for providing the propeller model.

\section{References}

[1] Das, H. and S. Kapuria, On the use of bend-twist coupling in full-scale composite marine propellers for improving hydrodynamic performance. Journal of Fluids and Structures, 2016. 61: p. 132-153.

[2] Husaini, M., Z. Samad, and M.R. Arshad. Optimum Design of URRG-AUV Propeller Using PVL. in 2nd Technical Seminar on Underwater System Technology: Breaking New Frontiers. 2008.

[3] Mizzi, K., et al., Design optimisation of Propeller Boss Cap Fins for enhanced propeller performance. Applied Ocean Research, 2017. 62: p. 210-222.

[4] Zhu, Z.-f. and S.-1. Fang, Numerical investigation of cavitation performance of ship propellers. Journal of Hydrodynamics, Ser. B, 2012. 24(3): p. 347-353.

[5] Rahman, A., M.R. Ullah, and M.M. Karim, Marine Propeller Design Method based on Lifting Line Theory and Lifting Surface Correction Factors. Procedia engineering, 2017. 194: p. 174-181.

[6] Epps, B., J. Ketcham, and C. Chryssostomidis. Propeller blade stress estimates using lifting line theory. in Proceedings of the 2010 Conference on Grand Challenges in Modeling \& Simulation. 2010. Society for Modeling \& Simulation International.

[7] Ekinci, S., A practical approach for design of marine propellers with systematic propeller series. Brodogradnja: Teorija i praksa brodogradnje i pomorske tehnike, 2011. 62(2): p. 123-129.

[8] Taheri, R. and K. Mazaheri, Hydrodynamic Optimization of Marine Propeller Using Gradient and Non-Gradient-based Algorithms. Acta Polytechnica Hungarica, 2013. 10(3): p. 221-237.

[9] Elghorab, M., et al. Experimental Study of Open Water Non-Series Marine Propeller Performance. in
Proceedings of World Academy of Science, Engineering and Technology. 2013. World Academy of Science, Engineering and Technology (WASET).

[10] Arazgaldi, R., A. Hajilouei, and B. Farhanieh, Experimental and numerical investigation of marine propeller cavitation. 2009.

[11] Prakash, S. and D.R. Nath, A computational method for determination of open water performance of a marine propeller. International Journal of Computer Applications, 2012. 58(12).

[12] Maghareh, M. and H. Ghassemi, Propeller Efficiency Enhancement by the Blade's Tip Reformation. American Journal of Mechanical Engineering, 2017. 5(3): p. 70-75.

[13] Ting, F.Y., et al., Development of Seakeeping Test and Data Processing System. International Journal of Computational Engineering Research (IJCER), 2015: p. 33-39.

[14] Fitriadhy, A., et al., Computational fluid dynamics investigation on total resistance coefficient of a highspeed" deep-V" catamaran in shallow water. International Journal of Automotive and Mechanical Engineering, 2017. 14: p. 4369-4382.

[15] Fitriadhy, A., et al., Computational fluid dynamics analysis on the course stability of a towed ship. Journal of Mechanical Engineering and Sciences, 2017. 11(3): p. 2919-2929.

[16] Colley, E., Analysis of Flow around a Ship Propeller using OpenFOAM. 2012, Thesis, Curtin University.

[17] Turunen, T., et al. Open-water computations of a marine propeller using openfoam. in ECFD VI-6th European Congress on Computational Fluid Dynamics, Barcelona, Spain, 20-25 July 2014. 2014.

[18] Felicjancik, J., et al., Numerical simulations of hydrodynamic open-water characteristics of a ship propeller. Polish Maritime Research, 2016. 23(4): p. 16-22.

[19] Sun, H., et al., Motion prediction of catamaran with a semisubmersible bow in wave. Polish Maritime Research, 2016. 23(1): p. 37-44.

[20] Shamsi, R., S. Soheili, and A. Hamooni. Hydrodynamic analysis of marine propellers using computational fluid dynamics. in Proceedings of the 17th international conference on mechanical engineering.

[21] Fitriadhy, A., N. Razali, and N. AqilahMansor, Seakeeping performance of a rounded hull catamaran in waves using CFD approach. Journal of Mechanical Engineering and Sciences 2017. 11(2): p. 2601-2614.

[22] Fitriadhy, A. and N.A. Adam, Heave and pitch motions performance of a monotricat ship in head-seas. International Journal of Automotive and Mechanical Engineering, 2017. 14: p. 4243-4258.

[23] Baek, D.-G., et al., Effects of the advance ratio on the evolution of a propeller wake. Computers \& Fluids, 2015. 118: p. 32-43.

[24] Deck, S., et al., Development and application of Spalart-Allmaras one equation turbulence model to three-dimensional supersonic complex configurations. 
Aerospace Science and Technology, 2002. 6(3): p. 171-183.

[25] Kostić, Ц́., Review of the Spalart-Allmaras turbulence model and its modifications to three-dimensional supersonic configurations. Scientific Technical Review, 2015. 65(1): p. 43-49.

[26] Hejlesen, M.M., et al. Implementation of the SpalartAllmaras turbulence model in the two-dimensional vortex-in-cell method. in 6th European Congress on Computational Methods in Applied Sciences and Engineering. 2012. Vienna University of Technology.

[27] Lorin, E., A. Ben Haj Ali, and A. Soulaimani. An accurate positivity preserving scheme for the SpalartAllmaras turbulence model. Application to aerodynamics. in 36th AIAA Fluid Dynamics Conference and Exhibit. 2006.

[28] International, N., FINE/Turbo v8. 7, user manual. 2009, NUMECA International Brussels.

[29] Salim, S.M. and S. Cheah. Wall Y strategy for dealing with wall-bounded turbulent flows. in Proceedings of the international multiconference of engineers and computer scientists. 2009. Citeseer.

[30] Martinez, J., et al., Aerodynamic analysis of wind turbine rotor blades. Task Q, 2015. 19(2): p. 129-140.

[31] Kamal, I.M. and T.M.A.T.M. Yusof, A CFD RANS Cavitation Prediction for Propellers. 2017.

[32] Folkner, D., Improvement in computational fluid dynamics through boundary verification and preconditioning. 2013.

[33] Husaini, M., Z. Samad, and M.R. Arshad, Autonomous underwater vehicle propeller simulation using computational fluid dynamic, in Computational Fluid Dynamics Technologies and Applications. 2011, InTech.

[34] Yeo, K.B. and W.Y. Hau, Fundamentals of Marine Propeller Analysis. Journal of Applied Sciences, 2014. 14(10): p. 1078-1082.

[35] Yeo, K.B., W.H. Choong, and W.Y. Hau, Prediction of propeller blade stress distribution through FEA. Journal of Applied Sciences, 2014. 14(22): p. 30463054. 